\title{
Uma crítica à substancialização do inconsciente
}

\section{A critique to the substantialization of the unconscious}

Desler Lacan apresenta em epígrafe: "Como o âmbar que preserva a mosca para nada saber de seu vôo". Essa frase está no prefácio, escrito por Lacan (1969), à publicação da primeira tese acadêmica sobre seu ensino: o livro de Anika Lemaire (1970). Uma advertência de Lacan: o mais inovador de seu ensino já estaria sendo esquecido.

Entre essas inovações esquecidas, destaco a seguir duas. No Seminário $O$ avesso da psicanálise, tratava-se de um crítica ao complexo de Édipo bem antes que Deleuze e Guattari saíssem com seu Anti-édipo. No Seminário Mais, Ainda, Lacan não teorizava

${ }^{* 1}$ Universidade Federal do Rio Grande do Sul - UFRGS (Porto Alegre, RS, Brasil). 


\section{RESENHAS BIBLIOGRÁFICAS}

a sexualidade nem em termos de gênero nem em termos de gozo, mas em termos de lógica discursiva. Enfim, Lacan estava visando uma teoria não substancialista da psicanálise. Para desontologizar a psicanálise, sua ferramenta era o conceito de significante, que já não era o da Linguística.

O sintoma é um significante, não uma palavra. Goldenberg chama nossa atenção para essa diferença, pois fora da palavra estaria o inefável. O Real nada tem a ver com o impossível de verbalizar, mas com o desencontro entre linguagem e referente.

O capítulo onde a primeira pessoa se faz mais presente é "Enquanto passam os anos". Esse capítulo tem vocação de transmissão psicanalítica. $\mathrm{O}$ autor conta que escreveu o título e depois se deu conta de que era uma tradução de As time goes by, nome da canção do filme Casablanca. O passado irrecuperável e o desencontro dos amantes desencontrados. Será de sua experiência que tentará transmitir ao leitor o que é a desubstancialização do inconsciente.

$\mathrm{O}$ que quer dizer "o sujeito enlaçado ao significante, ambos em mútua remissão?" (p. 260). Os psicanalistas admitem que a linguagem precede o sujeito, mas nem todos abandonam uma leitura animista e determinista inconsciente. "A psicanálise é o trabalho do discurso que transforma acaso em acontecimento" (p. 261).

No discurso do psicanalista, o significante existe em virtude de uma leitura. Quem diz ler, também diz escrever, por isso Lacan denomina 'letra' o significante localizado, determinado e registrado. Mas há uma distinção entre significante e letra. Em um relato de caso, se trata do que ficou registrado, a letra. Pois o significante não tem sobrevida posterior ao evento no qual existe. O que importa é que mesmo que o significante não se apresente em palavras, haja um leitor. O tempo do significante é o futuro do pretérito nas suas formas simples: eu seria, eu estaria, eu teria, eu haveria; ou compostas: eu teria sido, eu teria estado, eu teria tido, eu teria havido. Nesse sentido, o que teria sido pensado não deixará de continuar sendo pensado, quer aconteça ou não um evento. E, se depois que foi pensado (desejado), algo de fato aconteceu, mesmo assim poderia também não ter acontecido. Os dois eventos, o evento enquanto pensamento e o evento enquanto acontecimento, não estão ligados por relação de causa e efeito.

Outra forma de abordar a questão seria através da lógica. Começando pela retomada da questão da aleatoriedade no Seminário sobre a Carta roubada. Além disso, vale a leitura do conceito de abdução. Uma invenção ou abdução criativa, nos diz Umberto Eco, é comparável ao método do escultor 
Michelângelo, que dizia que desvendava na pedra a estátua que a matéria já circunscrevera. Também podemos relacionar essa distinção entre substancialização e aleatoriedade à descoberta que premiou o psicólogo Kahneman com o Nobel de Economia em 2002. Mlodinow divulgou essa pesquisa sobre as decisões ilógicas que as pessoas costumam tomar quando lêem relações de causa e efeito onde há apenas aleatoriedade.

Um analisante pode dizer duas coisas logicamente contraditórias em um breve intervalo de tempo, e acontece não ter como lembrar da primeira, que a contradiz, enquanto profere a segunda, a menos que haja um analista ali para lembrá-lo. É nisso que consiste levantar o recalcado, em saber juntar 'lé com cré'. Antes, 'lé com cré' configuravam o aparente verso e o anverso de uma Fita de Moebius. Juntar 'lé com cré' equivale ao corte longitudinal pela linha média de uma fita de Moebius. As duas faces serão discerníveis pelo analisante. Eis o famoso corte! Mas em que ele seria "sem palavras"? Em primeiro lugar, se 'lé com cré' já foram proferidos pelo analisante, o analista não precisa acrescentar nada. Em segundo lugar, o que interessa à interpretação é que "a significação produzida permita ao paciente perceber a qual significante ele está assujeitado" (p. 218).

Goldenberg apresenta uma interessante comparação entre transferência positiva e negativa. A transferência positiva permanece sempre algo assombrada pela sugestão. Conquanto muito difíceis, "as análises com um analista sub judice, quando não naufragam antes da sua hora, são as que chegam mais longe" (p. 284).

No final do livro, no capítulo "Exit", o autor apresenta três ensaios. Em um deles o dialoga com o livro de Butler, Problemas de gênero, para uma crítica à leitura das fórmulas da sexuação no Seminário Mais, Ainda. A noção de gênero é completamente estranha à psicanálise, pois o objeto que move o desejo carece de gênero. Para a psicanálise, o sexo não é natural nem dado, mas tampouco uma construção cultural de sentido, pois o sexo não faz o menor sentido. Portanto, o que se pode marcar em relação ao sexo é a impossibilidade de uma marcação na linguagem. Se toda diferença é simbólica, e o sexo escapa do simbólico, então a questão é trabalhar os impasses dos falaseres em relação ao sexo.

A edição do livro merece destaque pelas densas notas de rodapé; pelos avisos ao leitor para seguir leitura não linear; pelas ilustrações da topologia de superfícies, pelos quadros com trechos do livro em fonte aumentada; e, enfim, pelos vídeos acessíveis por código QR. 


\section{RESENHAS BIBLIOGRÁFICAS}

\section{Referências}

Eco, U. \& Sebeock, T. A. (1991). O signo de três. São Paulo, SP: Perspectiva.

Lacan, J. (1969) Preface au "Jacques Lacan" d'Anika Lemaire. Recuperado em 15 de maio, 2019, de <http://ecole-lacanienne.net/bibliolacan/pas-tout-lacan>.

Lacan, J. (1985). O seminário. Livro 20. Mais, ainda. Rio de Janeiro, RJ: Jorge Zahar. (Trabalho original publicado em 1972-1973).

Lacan, J. (1992). O Seminário, Livro 17, O avesso da psicanálise. Rio de Janeiro, RJ: Jorge Zahar. (Trabalho original publicado em 1969-1970).

Lacan, J. (1998). O seminário sobre 'A carta roubada'. In Escritos (pp. 13-66). Rio de Janeiro, RJ: Jorge Zahar.

Mlodinow, L. (2008). O andar do bêbado. Rio de Janeiro, RJ: Zahar.

Citação/Citation: D’Agord, M. R. de L. (2019, junho). Uma crítica à substancialização do inconsciente. Resenha do livro Desler Lacan. Revista Latinoamericana de Psicopatologia Fundamental, 22(2), 398-402. http://dx.doi.org/10.1590/1415-4714.2018v22n2p398.13.

Editora/Editor: Profa. Dra. Ana Maria Galdino Raimundo Oda

Submetido/Submitted: 26.10.2018 / 10.261.2018 Aceito/Accepted: 21.1.2019 / 1.21.2019 
Copyright: (C) 2009 Associação Universitária de Pesquisa em Psicopatologia Fundamental/ University Association for Research in Fundamental Psychopathology. Este é um artigo de livre acesso, que permite uso irrestrito, distribuição e reprodução em qualquer meio, desde que o autor e a fonte sejam citados / This is an open-access article, which permits unrestricted use, distribution, and reproduction in any medium, provided the original authors and sources are credited.

\section{Marta Regina de Leão D’Agord}

Doutora em Psicologia; Professora do PPG Psicanálise: Clínica e Cultura da Universidade Federal do Rio Grande do Sul - UFRJ (Porto Alegre, RS, Br)

Rua Riveira, 600

90670-160 Porto Alegre, RS, Br

04035-001 São Paulo, SP, Br

https://orcid.org/0000-0003-0379-5323

marta.dagord@ufrgs.br

This is an open-access article, which permits unrestricted use, distribution,

(cc) BY-NC and reproduction in any medium for non-commercial purposes provided the original authors and sources are credited. 